\title{
Autoantibodies in Melanoma-Associated Retinopathy Target TRPM1 Cation Channels of Retinal ON Bipolar Cells
}

\author{
Anuradha Dhingra, ${ }^{1}$ Marie E. Fina, ${ }^{1}$ Adam Neinstein, ${ }^{1}$ David J. Ramsey, ${ }^{2}$ Ying Xu, ${ }^{3}$ Gerald A. Fishman, ${ }^{4}$ \\ Kenneth R. Alexander, ${ }^{4}$ Haohua Qian, ${ }^{4}$ Neal S. Peachey, ${ }^{5,6,7}$ Ronald G. Gregg, ${ }^{8,9}$ and Noga Vardi ${ }^{1}$ \\ ${ }^{1}$ Department of Neuroscience, University of Pennsylvania School of Medicine, Philadelphia, Pennsylvania 19104, 2The Wilmer Eye Institute, Johns Hopkins \\ University, Baltimore, Maryland 21287, ${ }^{3}$ Joint Laboratory for Brain Function and Health, Jinan University and the University of Hong Kong, Jinan \\ University, Guangzhou 510632, China, ${ }^{4}$ Ophthalmology and Visual Sciences, University of Illinois at Chicago, Chicago, Illinois 60612, ${ }^{5} \mathrm{Cleveland}$ Veterans \\ Affairs Medical Center, Cleveland, Ohio 44196, ${ }^{6}$ Cole Eye Institute, Cleveland Clinic Foundation, Cleveland, Ohio 44195, ${ }^{7}$ Department of Ophthalmology, \\ Cleveland Clinic Lerner College of Medicine of Case Western Reserve University, Cleveland, Ohio 44106, and Departments of ${ }^{8}$ Biochemistry and Molecular \\ Biology and ${ }^{9}$ Ophthalmology and Visual Sciences, University of Louisville, Louisville, Kentucky 40202
}

Melanoma-associated retinopathy (MAR) is characterized by night blindness, photopsias, and a selective reduction of the electroretinogram b-wave. In certain cases, the serum contains autoantibodies that react with ON bipolar cells, but the target of these autoantibodies has not been identified. Here we show that the primary target of autoantibodies produced in MAR patients with reduced b-wave is the TRPM1 cation channel, the newly identified transduction channel in ON bipolar cells. Sera from two well characterized MAR patients, but not from a control subject, stained human embryonic kidney cells transfected with the TRPM1 gene, and Western blots probed with these MAR sera showed the expected band size $(\sim 180 \mathrm{kDa})$. Staining of mouse and primate retina with MAR sera revealed immunoreactivity in all types of ON bipolar cells. Similar to staining for TRPM1, staining with the MAR sera was strong in dendritic tips and somas and was weak or absent in axon terminals. This staining colocalized with GFP in Grm6-GFP transgenic mice, where GFP is expressed in all and only ON bipolar cells, and also colocalized with $\mathrm{G} \alpha_{\mathrm{o}}$, a marker for all types of $\mathrm{ON}$ bipolar cells. The staining in ON bipolar cells was confirmed to be specific to TRPM1 because MAR serum did not stain these cells in a Trpm $1^{-1-}$ mouse. Evidence suggests that the recognized epitope is likely intracellular, and the sera can be internalized by retinal cells. We conclude that the vision of at least some patients with MAR is compromised due to autoantibody-mediated inactivation of the TRPM1 channel.

\section{Introduction}

Melanoma-associated retinopathy (MAR) is an infrequently encountered condition seen in some cutaneous melanoma patients, who experience a rapid onset of night blindness and other visual abnormalities (Berson and Lessell, 1988; Alexander et al., 1992; Milam et al., 1993; Keltner et al., 2001; Heckenlively and Ferreyra, 2008). The dark-adapted electroretinogram (ERG) of these patients typically has a normal a-wave but a greatly reduced b-wave, consistent with a defect in neurotransmission from photoreceptors to ON bipolar cells, which generate the b-wave component. The symptoms of night blindness and the selective ERG b-wave reduction resemble the complete form of congenital stationary night blindness (cCSNB), which is caused by mutations in genes

\footnotetext{
Received Nov. 16, 2010; revised Jan. 19, 2011; accepted Jan. 27, 2011.

This work was supported by National Institutes of Health (NIH) Grant EY11105 (N.V.), NIH Grant EY08301 (K.A.), NIH-National Eye Institute Grant P30 EY01583 (University of Pennsylvania), the Illinois Society for the Prevention of Blindness (D.J.R.), the Foundation Fighting Blindness (G.A.F., N.S.P.), the Department of Veterans Affairs (N.S.P.), and Research to Prevent Blindness (N.S.P.). We thank Narender K. Dhingra for help with injection of peanut agglutinin.

Correspondence should be addressed to Dr. Anuradha Dhingra, 123 Anatomy/Chemistry Building, Philadelphia, PA 19104-6058. E-mail: dhingra@mail.med.upenn.edu.

H. Qian's present address: National Eye Institute, Bethesda, MD 20892.

DOI:10.1523/JNEUROSCI.6007-10.2011

Copyright $\odot 2011$ the authors $\quad 0270-6474 / 11 / 313962-06 \$ 15.00 / 0$
}

that mediate the transduction cascade in $\mathrm{ON}$ bipolar cells [for review, see McCall and Gregg (2008) and Morgans et al. (2010)].

Based on the observation that the serum of MAR patients reacts with rod bipolar cells (Milam et al., 1993), it was originally proposed that MAR results from autoantibodies that circulate in the patient's serum. In support of this proposal, injection of purified IgG from MAR patients into monkey eyes reduces the amplitude of the ERG b-wave (Lei et al., 2000), and suppression of the immune response may induce partial visual recovery (Keltner et al., 2001). Efforts to identify the antigens that are targeted by the autoantibodies have revealed a number of photoreceptor proteins, but none specific to ON bipolar cells (Potter et al., 2002; Hartmann et al., 2005; Lu et al., 2009).

TRPM1 (also known as melastatin 1, or MLSN1) was recently identified as the cation channel that mediates the light response in ON bipolar cells (Morgans et al., 2009; Shen et al., 2009; Koike et al., 2010). Mutations in TRPM1 have been linked to human cCSNB (Audo et al., 2009; Li et al., 2009; van Genderen et al., 2009). Moreover, Trpm1 knock-out mice display ERG b-wave reductions, as does the Appaloosa horse model of cCSNB, in which the night blindness and coat-spotting traits have been linked to the TRPM1 locus (Bellone et al., 2008, 2010). These observations, the expression of TRPM1 in melanocytes, and its downregulation in melanoma cells (Duncan et al., 2001; Hammock et al., 2006) suggest that MAR may involve the generation 

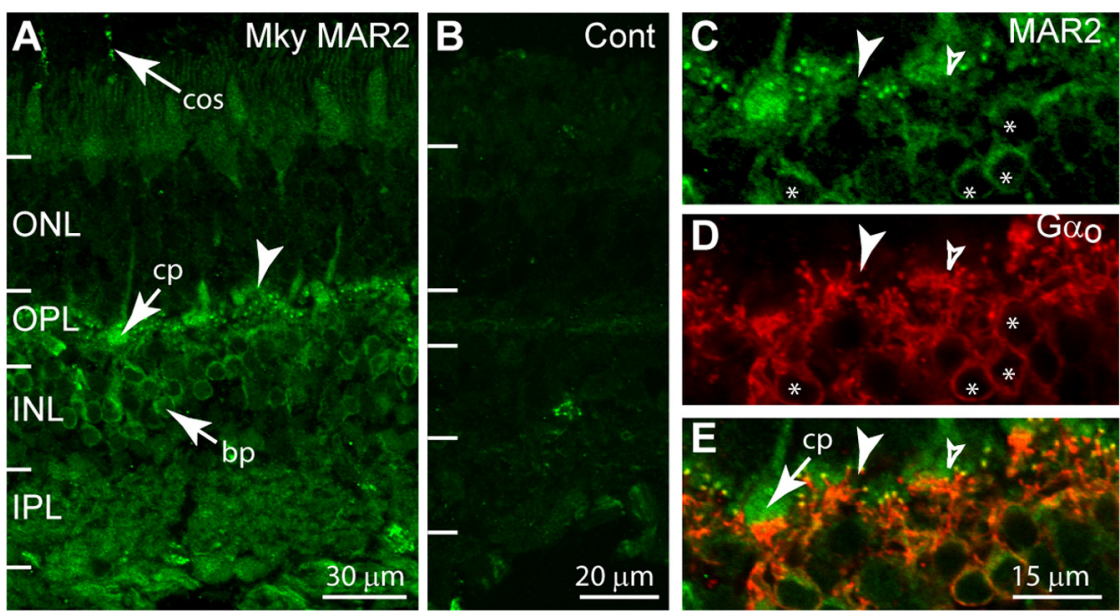

microscope. Description of immunostaining results is based on at least three independent staining experiments. Cell count on double labeled slices was performed manually on $z$-stacks using Fluoview.

Western blottings. Protein from frozen retina or HEK cells was prepared as described previously (Dhingra et al., 2008). After electrophoresis and protein transfer, the membranes were incubated in MAR serum (diluted 1:2000) or anti-TRPM1 antibody (diluted 1:7500) overnight at $4^{\circ} \mathrm{C}$ followed by secondary antibody for $3 \mathrm{~h}$ at room temperature.

\section{Results}

Certain MAR sera label retinal rod and ON cone bipolar cells

Figure 1. MAR sera target retinal rod and ON cone bipolar cells (monkey). $A$, MAR2 serum applied to monkey retina stained cone outer segments (cos); structures in the outer plexiform layer (OPL), which include strong puncta corresponding to dendritic tips of bipolar cells (arrowhead) and coneterminals (also called cone pedicles, cp); and bipolar somas (bp) in the inner nuclear layer (INL). Diffuse staining in the inner plexiform layer (IPL) was also observed. $\boldsymbol{B}$, Control serum applied to monkey retina revealed no staining. $\mathbf{C}-\boldsymbol{E}$, Coimmunostaining with MAR2 serum and $G \alpha_{0}$ antibody applied to monkey retina. All $G \alpha_{0}$-stained cells were also stained with the MAR2 serum ( ${ }^{*}$ ). The filled arrowhead points to a dendritic tip of a rod bipolar cell (identified by its location higher in the $\mathrm{OPL}$ ), and empty arrowheads point to dendritic tips of $\mathrm{ON}$ cone bipolar cells [identified as bright dots located at the bottom of the cone pedicle; these are difficult to see because the cone pedicle (cp, arrow) is also stained by this MAR serum]. ONL, Outer nuclear layer.

We tested sera obtained from three well characterized MAR patients who had a normal ERG a-wave but reduced b-wave. To identify the immunoreactive retinal cells, sera were first applied to monkey retinas. Both MAR1 and MAR2 sera, but not MAR3 serum, yielded distinct staining of bipolar cell somas and dendrites (Fig. 1A). Applying control serum gave no staining (Fig. $1 B$ ). To determine whether

of TRPM1 antibodies. In the present report, we present evidence in support of this hypothesis.

\section{Materials and Methods}

Antibodies, sera, and plasmids. Sera were obtained following informed consent from three well characterized male MAR patients (MAR1-3), and one visually normal male subject. MAR1 is the patient described by Alexander et al. (1992) and is also Patient 2 of Milam et al. (1993); MAR2 is Patient 2 of Alexander et al. $(2002,2004)$; and MAR 3 is Patient 1 of Alexander et al. (2002, 2004).

The primary antibodies used included the following: anti-TRPM1 raised against the $\mathrm{C}$ terminus of human TRPM1 (Sigma; catalog no. HPA014785), mouse anti-G $\alpha_{\mathrm{o}}$ (Millipore; catalog no. MAB3073), anti c-myc (9E10) (Developmental Studies Hybridoma Bank), and anti$\mathrm{GABA}_{\mathrm{A}}$ raised against the $\beta 2 / 3$ subunit of the $\mathrm{GABA}_{\mathrm{A}}$ receptor (Millipore Bioscience Research Reagents Int.; clone BD17). The plasmid encoding human TRPM1 fused to myc tag was a gift from Dr. Denise Montell (Johns Hopkins School of Medicine, Baltimore, MD) and plasmid encoding neuropilin 1 fused to a myc tag was a gift from Dr. Jonathan Raper (University of Pennsylvania, Philadelphia, PA).

Sample preparation and immunocytochemistry. Fixed or frozen monkey retinas (Macaca fascicularis) (from males and females) were obtained from Covance Research Products following unrelated experiments. Male and female mouse tissue was from the wild-type C57BL/6 strain, transgenic Grm6-GFP mice (Dhingra et al., 2008), or Trpm1 knock-out mice (as described by Shen et al., 2009) (two males and one female). Retinas were fixed in $4 \%$ paraformaldehyde in phosphate buffer for 10, 30, or 60 min. Radially cut cryosections or fixed HEK cells were immunostained as described previously (Dhingra et al., 2008). MAR sera were diluted 1:100 to 1:300 in blocking buffer. To determine whether the recognized TRPM1 epitope is intracellular or extracellular, freshly fixed retina was embedded in $4 \%$ agarose and sectioned with a Vibratome at $200 \mu \mathrm{m}$ thickness; sections were incubated in MAR sera or primary antibody for $10 \mathrm{~d}$.

For internalization tests, live retinal slices were incubated in different sera diluted in oxygenated Ames medium for variable durations. Slices were then rinsed, fixed, and incubated in a secondary antibody. In one experiment, a mouse eye was injected intravitreally with $1.5 \mu$ l of MAR2 mixed with fluorescein-conjugated peanut agglutinin $(1.5 \mu \mathrm{g})$, which marked the injection site. The retina was fixed and viewed $24 \mathrm{~h}$ later. For HEK cells, transfection was performed using Lipofectamine reagent (Invitrogen). Sections were photographed with an Olympus FV-1000 confocal only rod bipolar cells or all ON bipolar cells were stained, we costained for the G-protein subunit $\mathrm{G} \alpha_{\mathrm{o}}$ [a marker for ON bipolar cells (Vardi, 1998; Dhingra et al., 2002)] and found that practically all cell bodies labeled by $\mathrm{G} \alpha$ o were also stained for MAR2 serum (149/151; two experiments) (Fig. 1C-E). Eight cells that stained for MAR2 were unlabeled for $\mathrm{G} \alpha$, likely because somatic staining for $\mathrm{G} \alpha_{\mathrm{o}}$ is often weak (Vardi, 1998). Thus, both rod bipolar and $\mathrm{ON}$ cone bipolar cells are targeted by MAR2. Although bipolar cell staining was robust, the relative intensity of the stain varied; e.g., the staining of bipolar dendrites in the mouse appeared more intense with MAR1 serum than with MAR2, while MAR2 gave stronger staining in monkey. The intensity of additional stained structures that do not belong to bipolar cells also varied; e.g., in mouse, MAR1, but not MAR2, showed some staining in ganglion cells and axon fibers, and in monkey (but not in mouse), MAR2 stained cone outer segments and both sera stained cone terminals.

A similar pattern of bipolar cell staining was also obtained in baboon and rat. The autoantibodies in MAR1 serum are of the IgG type, because purified IgG gave similar labeling (not shown). To confirm purity of the fraction, we applied anti-IgM secondary antibodies, and this did not reveal any staining.

\section{Autoantibodies in MAR1 and MAR2 sera target TRPM1}

To determine whether MAR sera recognize TRPM1, we transfected HEK cells with human TRPM1 fused to myc. Immunostaining these cells with the sera showed that both MAR1 and MAR2 sera stained the TRPM1 transfected cells and, as with antiTRPM1, the staining was not restricted to the membrane, but was present also in the cytosol (Fig. $2 A, B$ ). We verified that each stained cell expressed TRPM1 by costaining for myc: colocalization was $\sim 100 \%$ (Fig. $2 C, D$ ). MAR sera did not stain untransfected HEK cells, nor did the control serum stain TRPM1-transfected cells (Fig. 2E, F). To ensure that the MAR sera did not recognize the myc tag, we transfected HEK cells with an unrelated protein (neuropilin1) fused to myc; the anti-myc antibody stained transfected cells, but the MAR sera did not (Fig. 2G,H). 
Next we tested whether MAR sera recognize TRPM1 by Western blotting. Applying the MAR sera to TRPM1transfected HEK cell protein gave a band at the predicted size ( $180 \mathrm{kDa})$ of TRPM1 (Xu et al., 2001; Koike et al., 2010), and this was lacking from untransfected HEK cells (Fig. 2I, middle and left lanes, arrow). The control serum did not show this band in TRPM1-transfected HEK cells (Fig. 2I, right lane). When mouse and monkey retinas were probed with the MAR sera, several bands appeared, but none was at $180 \mathrm{kDa}$. We confirmed that the mobility of TRPM1 in monkey retina is $180 \mathrm{kDa}$ by probing the Western blots of transfected HEK cells and monkey retina with anti-TRPM1 (Fig. $2 \mathrm{~J}$ ). We conclude that the MAR sera do not easily recognize the denatured endogenous TRPM1.

The experiments presented so far establish that the sera of MAR1 and MAR2 recognize TRPM1, but do not prove that the staining of bipolar cells by the MAR serum represents recognition of TRPM1. Theoretically, the TRPM1 in these cells may go unrecognized, and the observed staining in bipolar cells may be due to an additional autoantibody in the serum. We addressed this issue in the mouse. First, we verified that MAR sera but not a control serum stain bipolar cells (data not shown). Then we identified the type of bipolar cells by applying the MAR sera to retinal sections obtained from Grm6-GFP transgenic mice, which express GFP in all and only $\mathrm{ON}$ bipolar cells (Fig. $3 A-C$ ). We noted almost complete overlap of MAR sera and GFP staining ( 184 cells out of 195 GFP-positive cells showed MAR1 staining and 7 cells stained only for MAR1, three experiments; 52 out of 65 GFP-positive cells stained for MAR2, 1 cell stained only for MAR2, two experiments). Similar results were obtained by double staining for $\mathrm{G} \alpha_{\mathrm{o}}$ (data not shown). This indicates that MAR staining in the inner nuclear layer is mostly restricted to $\mathrm{ON}$ bipolar cells.

Next, we applied the MAR sera to retinal sections obtained from $\operatorname{Trpm} 1^{-1-}$ mice (three different animals). In the $\operatorname{Trpm} 1^{-1-}$ retina, neither MAR1 nor MAR2 serum stained ON bipolar cells (Fig. 3D-I). This suggests that, in bipolar cells, only TRPM1 is recognized.
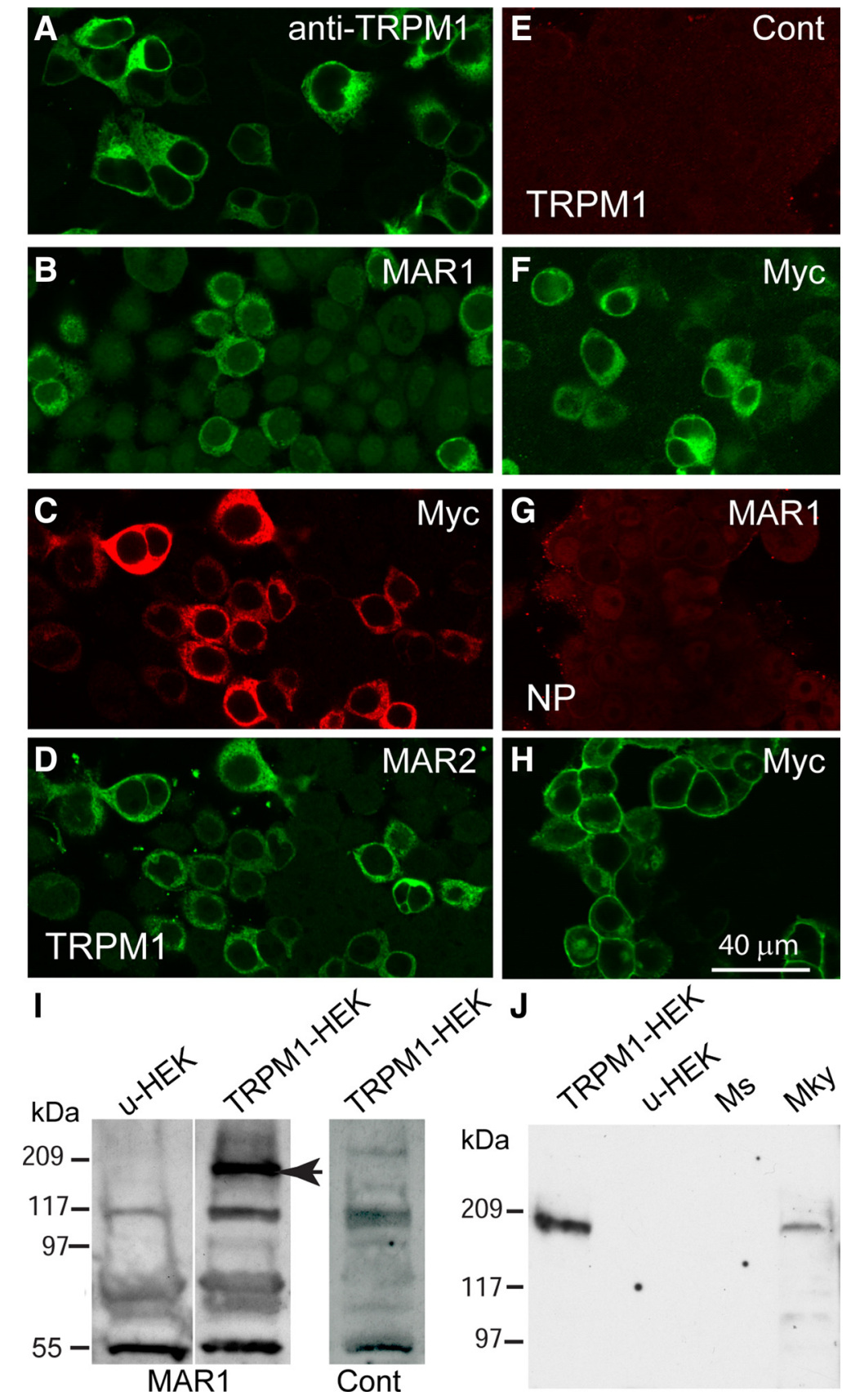

Figure 2. Autoantibodies in MAR1 and MAR2 sera recognize TRPM1 in cell culture. $A, B$, TRPM1-transfected HEK cells stained with antibody against human TRPM1 $(\boldsymbol{A})$ or with MAR1 $(\boldsymbol{B})$. Most of the stain is localized intracellularly. $\boldsymbol{C}, \boldsymbol{D}$, TRPM1-transfected HEK cells costained with anti-myc antibody $(\boldsymbol{C})$ and MAR2 (D). $\boldsymbol{E}, \boldsymbol{F}$, TRPM1-transfected HEK cells costained with a control serum $(\boldsymbol{E})$ and anti-myc antibody $(\boldsymbol{F}) . \boldsymbol{G}, \boldsymbol{H}$, Neuropilin.myc-transfected HEK cells costained with MAR1 serum $(\boldsymbol{G})$ and anti-myc antibody $(\boldsymbol{H})$. MAR1 did not recognize the myc tag. $I$, Proteins (20 $\mu \mathrm{g}$ per lane) homogenized from untransfected HEK cells (u-HEK) and from TRPM1-transfected HEK cells were blotted with MAR1 serum. First and second lanes are from the same blot. The arrowhead points to the $180 \mathrm{kDa}$ TRPM1 band. Third lane, TRPM1-transfected HEK cell proteins probed with control serum (cont); the $180 \mathrm{kDa}$ band is not present.J, First and second lanes, TRPM1-transfected (TRPM1-HEK) and untransfected (u-HEK) HEK cells proteins (10 $\mu \mathrm{g}$ per lane) were probed with anti-TRPM1. A band at $180 \mathrm{kDa}$ is seen in the transfected HEK and is absent from the untransfected. Third and fourth lanes, Mouse (Ms) and monkey (Mky) retinal protein (44 $\mu \mathrm{g}$ per lane) were probed with the anti-TRPM1 antibody. A band of the correct size is seen only in the monkey retina.
The TRPM1 epitopes for the autoantibodies are likely to be in the intracellular domain

To determine whether the antibody recognizes an intracellular or extracellular domain, we incubated TRPM1-transfected HEK cells in the MAR sera with or without Triton X-100. In the absence of Triton X-100, only a weak background staining was seen (Fig.
$4 A, B)$. This lack of staining may indicate that the TRPM1 epitope is intracellular, but it may also indicate a failure of the expressed TRPM1 to integrate into the transfected HEK cell surface. We have thus examined this question in retina, where TRPM1 must be localized to the cell surface to mediate the light response. Staining for MAR1 in the presence of Triton X-100 was strong in 

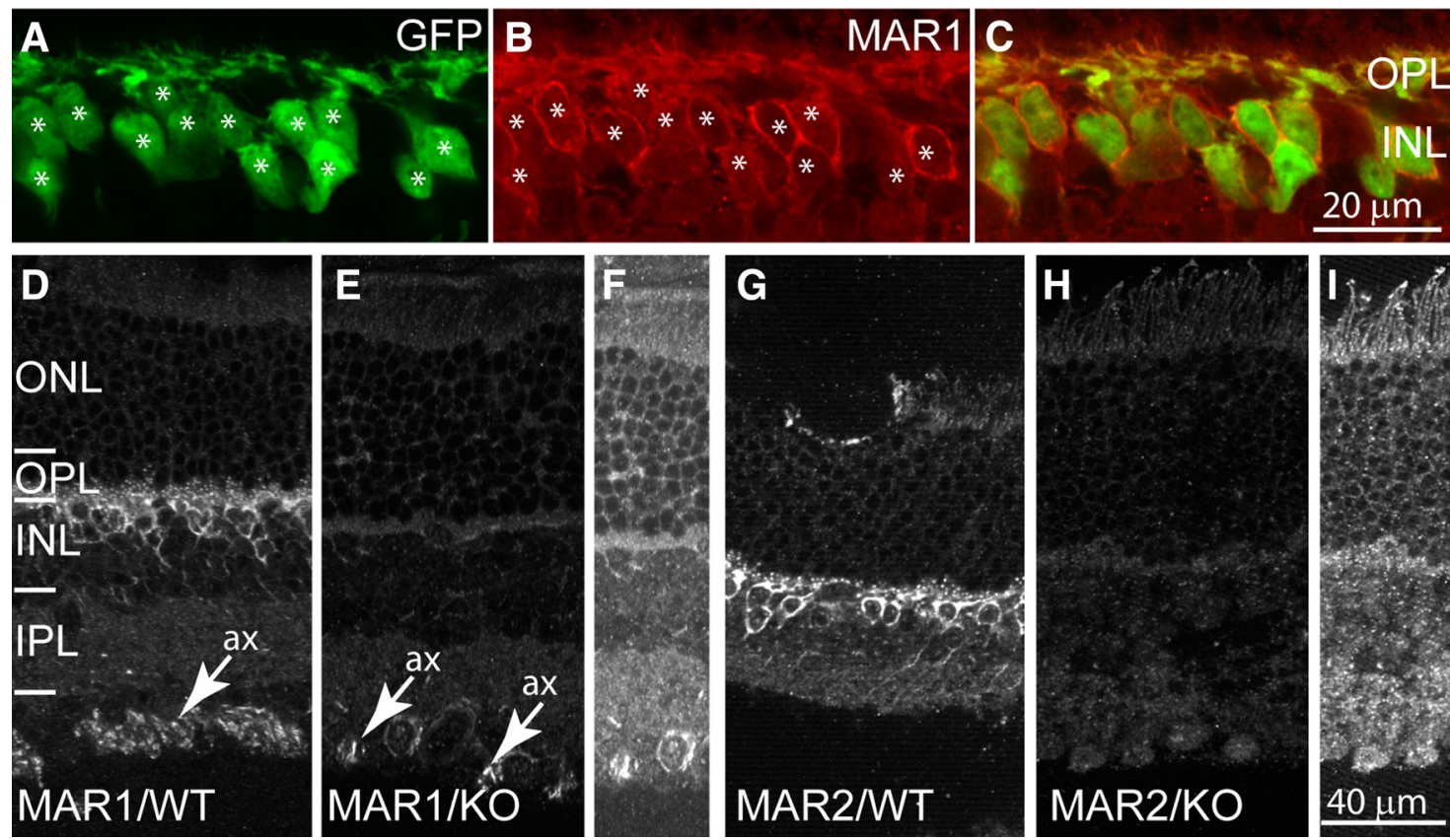

Figure 3. In mouse ON bipolar cells, autoantibodies in MAR sera target only TRPM1. A-C, MAR1 serum applied to retina from Grm6-GFP transgenic mouse marks all ON bipolar cells. In this field, all GFP-expressing cells were stained with the MAR1 serum $\left.{ }^{*}\right) . \boldsymbol{D}, \boldsymbol{E}$, MAR1 serum applied to retinas of wild-type $(\boldsymbol{D})$ or $\operatorname{Trpm} 1^{-1-}$ littermate $(\boldsymbol{E})$ mouse shows that the staining in bipolar cells was eliminated in the knock-out mouse, but the staining in ganglion cell axons (ax) was not. Retinas in $\boldsymbol{D}$ and $\boldsymbol{E}$ were imaged with same settings. $\boldsymbol{F}$, Same section as $\boldsymbol{E}$ with increased offset to show retinal structure. $\mathbf{G}-\mathbf{I}$, Same as $\mathbf{D}-\boldsymbol{F}$ using MAR2 serum.

both somas and fine dendrites; however, the antibody penetrated only down to a depth of $\sim 9 \mu \mathrm{m}$. Omitting Triton X-100 retained somatic staining down to a depth of 5-6 $\mu \mathrm{m}$ (because these were cut open by sectioning), but it totally abolished dendritic staining (Fig. 4C,D). Staining for MAR2 in the absence of Triton X-100 gave high background, but no specific staining. In contrast, staining for $\mathrm{GABA}_{\mathrm{A}}$ receptor [raised against an extracellular epitope (Vardi and Sterling, 1994)] remains strong in dendritic tips of cone bipolar cells (and in the inner plexiform layer) even in the absence of Triton X-100 (Fig. 4E,F). These experiments indicate that MAR antibodies recognize intracellular epitopes on the TRPM1 channel, but do not exclude the possibility that a small fraction of the antibody clones are against extracellular epitopes, which are too few to give above-background staining.

We have further tested whether the antibodies can be internalized into retinal cells. Incubation of live retinal slices in MAR2 revealed that many horizontal and amacrine cells internalized the antibodies within $1 \mathrm{~h}$, while photoreceptors and bipolar cells required a longer period (Fig. 4G-I). The obtained staining is not due to stickiness of the secondary antibody because incubation in normal horse or goat sera or just in Ames medium followed by anti-human secondary did not result in any staining. However, these sera, as well as normal human serum, were also internalized, as revealed by using the appropriate secondary antibodies. Injecting MAR2 intravitreally and observing the retina $24 \mathrm{~h}$ later also showed internalization, albeit in a smaller fraction of cells.

\section{Discussion}

It has been known for $\sim 20$ years that some patients with MAR develop autoantibodies against proteins specific to retinal rod bipolar cells (Milam et al., 1993; Weinstein et al., 1994; Kellner et al., 1995; Adamus, 2009; Lu et al., 2009). Efforts to identify the antigen in bipolar cells have, until now, been unsuccessful. Here we show that certain MAR sera target TRPM1, the nonselective cation channel that is required for light responses in all types of ON bipolar cell (Morgans et al., 2009; Koike et al., 2010). This conclusion is supported by immunostaining of TRPM1transfected HEK cells with MAR sera, immunostaining of all types of ON bipolar cells in monkey and wild-type mouse retina, and absence of this immunostaining in $\operatorname{Trpm} 1^{-/-}$retina.

\section{Different subtypes of MAR disease}

The MAR condition was originally diagnosed based on the visual experience of night blindness, photopsias, and a selective reduction of the ERG b-wave. However, clinical diagnosis does not always include ERG recordings, and consequently, certain diagnosed cases may not be restricted to a bipolar cell dysfunction. Indeed several studies identified photoreceptor proteins as the MAR serum targets (Potter et al., 2002; Hartmann et al., 2005; Lu et al., 2009). ERG recordings could potentially differentiate between cases in which the primary target is a photoreceptor or a bipolar cell protein. If photoreceptors are targeted, ERG recordings are expected to show proportionally diminished a- and b-waves [as in Lu et al. (2009) for MAR patients]. If bipolar cell proteins are the primary targets, ERG recordings are expected to show a "negative" configuration with selective b-wave reductions but near-normal a-waves (Alexander et al., 1992; Keltner et al., 2001; Alexander et al., 2002). The situation is likely to be more complex, as Potter et al. (2002) reported a case of MAR in which ERG was negative but the patient's serum contained antibodies against transducin and did not label bipolar cells. In the future, it will be important to discriminate MAR subtypes by their autoantibodies rather than by ERG and vision tests alone. Because TRPM1 is the only bipolar cell protein implicated in MAR so far, we suggest referring to cases where bipolar cells are targeted as $\mathrm{MAR}_{\mathrm{TRPM1}}$. The value of discriminating MAR subtypes by targeted antigens will further increase when it becomes possible to specifically eliminate disease-causing autoantibodies from patients' blood. 
Possible causes of retinopathy

in MAR $_{\text {TRPM1 }}$

It is most likely that circulating antibodies bind the TRPM 1 channel on the ON bipolar cells and either directly block the channel or indirectly interfere with the cells' signal transduction, thereby leading to a loss of night vision and a reduced ERG b-wave. Most cases of MAR report an onset of night blindness (nyctalopia); this is probably because night vision is mediated by the rod bipolar cells, which comprise the majority of ON bipolar cells. In addition to nyctalopia, MAR patients exhibit some impairment of daylight vision (Keltner and Thirkill, 1998; Keltner et al., 2001; Alexander et al., 2002, 2004; Heckenlively and Ferreyra, 2008), reflecting dysfunction in the ON class of cone bipolar cells, which also use TRPM1 (Morgans et al., 2009). Any relative preservation of conemediated vision in MAR patients would be achieved via unaffected OFF bipolar cells. Mechanistically, the MAR antibodies could interfere with the signaling by binding either extracellular or intracellular epitopes on the TRPM1 channel. Our experiments suggest that the TRPM1 epitope recognized by MAR sera is intracellular, in which case, autoantibodies would have to be internalized before they can impact $\mathrm{ON}$ bipolar cell function. Internalization of several antibodies including normal IgGs has been shown previously (Adamus et al., 1997, 1998; Shiraga and Adamus, 2002) as well as in our study.

\section{Possible causes of}

\section{MAR-related autoimmunity}

In many cases of MAR, the autoantibodies target photoreceptor proteins (Bazhin et al., 2007). It has been found that healthy melanocytes transcribe many photoreceptor mRNAs, and when these cells become malignant, they start to express these proteins. Because the retina is immune-privileged, the body does not recognize these proteins as self and produces autoantibodies, possibly to fight the cancer cells. This explanation does not fit well with the $\mathrm{MAR}_{\mathrm{TRPM} 1}$ disease type because TRPM1 is expressed in normal melanocytes, and in fact is downregulated in melanoma (Duncan et al., 2001). If, however, downregulation of TRPM1 is a bodily defense mechanism directed against metastatic melanocytes in aggressive melanoma, the generation of anti-TRPM1 antibodies can contribute to this defense.

\section{References}

Adamus G (2009) Autoantibody targets and their cancer relationship in the pathogenicity of paraneoplastic retinopathy. Autoimmun Rev 8:410-414.
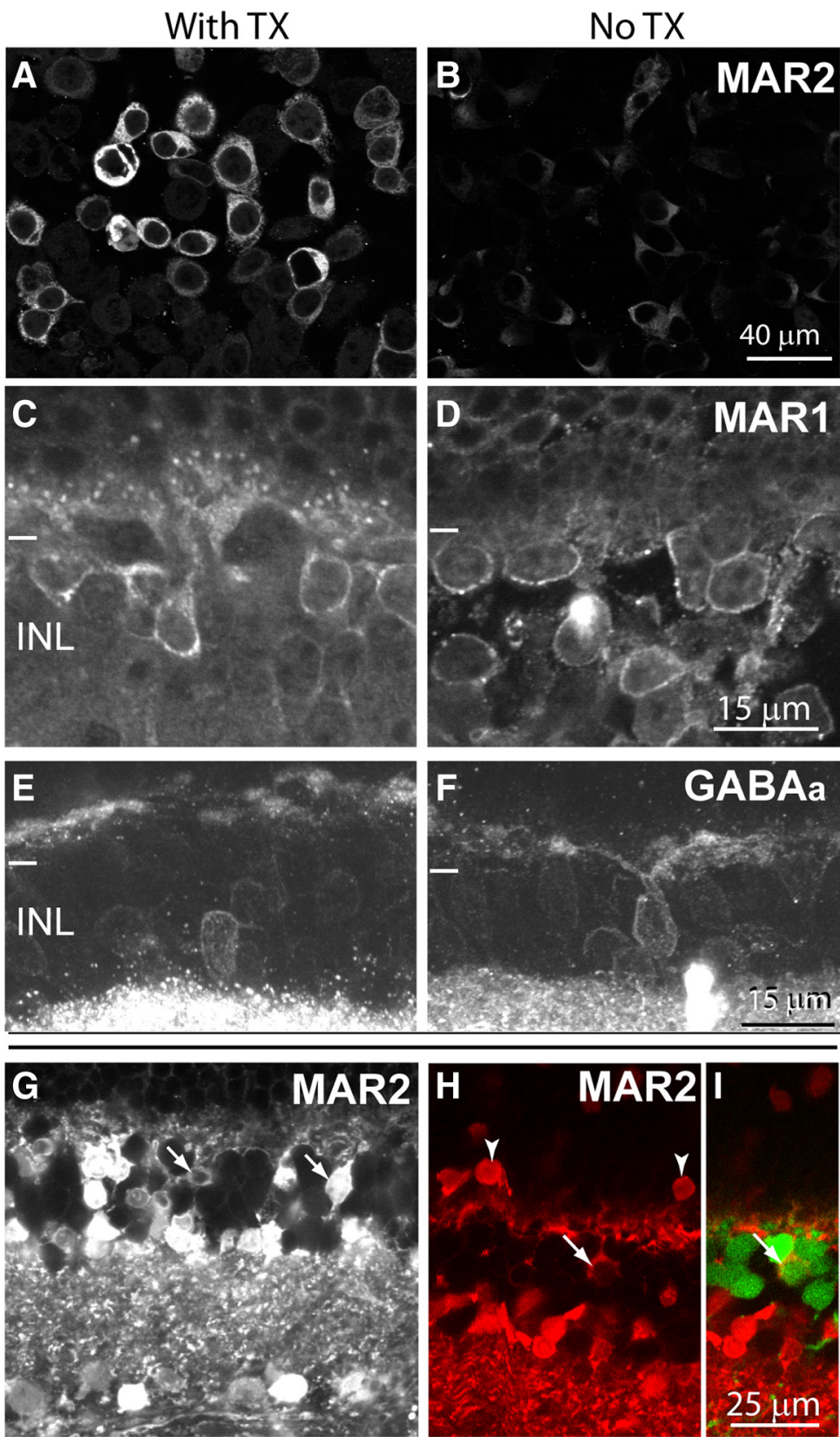

Figure 4. The epitope recognized by the MAR sera is intracellular and MAR serum is internalized. $A-D, M A R$ sera were applied to TRPM1-transfected HEK cells $(\boldsymbol{A}, \boldsymbol{B})$ or to Vibratome sections of mouse retina $(\boldsymbol{C}, \boldsymbol{D})$ either in the presence of the detergent Triton X-100 (left column) or in its absence (right column). In HEK cells, when Triton X-100 was omitted, only background staining was observed. In mouse retina, although somas of bipolar cells did stain when Triton X-100 was omitted (because the somas are large and most were cut open by the sectioning), dendrites or dendritic tips remained unstained even close to the section surface. Each pair $(\boldsymbol{A}-\boldsymbol{B}, \boldsymbol{C}-\boldsymbol{D})$ was imaged with same settings. $\boldsymbol{E}, \boldsymbol{F}$, Immunoreactivity to $\mathrm{GABA}_{A}$ receptor using an antibody against an extracellular epitope is similar for sections treated with (left) or without (right) Triton X-100. Both images represent a collapse of 18 confocal planes (spanning $18 \mu \mathrm{m}$ ) obtained under the same laser and gain settings and without contrast enhancement. $G-I$, Live retinal slices from a wild-type $(\boldsymbol{G})$ or Grm6-GFP transgenic $(\boldsymbol{H}, \boldsymbol{I})$ mouse after incubation in MAR2 for $3 \mathrm{~h}$. Most amacrine and horizontal cells and some bipolar cells (arrows) and photoreceptors (arrowheads) internalized the serum. $\boldsymbol{I}$, A merged region of $\boldsymbol{H}$ showing a stained $\mathrm{ON}$ bipolar cell (green).
Adamus G, Machnicki M, Seigel GM (1997) Apoptotic retinal cell death induced by antirecoverin autoantibodies of cancer-associated retinopathy. Invest Ophthalmol Vis Sci 38:283-291.

Adamus G, Machnicki M, Elerding H, Sugden B, Blocker YS, Fox DA (1998) Antibodies to recoverin induce apoptosis of photoreceptor and bipolar cells in vivo. J Autoimmun 11:523-533.

Alexander KR, Fishman GA, Peachey NS, Marchese AL, Tso MO (1992) 'On' response defect in paraneoplastic night blindness with cutaneous malignant melanoma. Invest Ophthalmol Vis Sci 33:477-483. 
Alexander KR, Barnes CS, Fishman GA, Milam AH (2002) Nature of the cone ON-pathway dysfunction in melanoma-associated retinopathy. Invest Ophthalmol Vis Sci 43:1189-1197.

Alexander KR, Barnes CS, Fishman GA, Pokorny J, Smith VC (2004) Contrast-processing deficits in melanoma-associated retinopathy. Invest Ophthalmol Vis Sci 45:305-310.

Audo I, Kohl S, Leroy BP, Munier FL, Guillonneau X, Mohand-Saïd S, Bujakowska K, Nandrot EF, Lorenz B, Preising M, Kellner U, Renner AB, Bernd A, Antonio A, Moskova-Doumanova V, Lancelot ME, Poloschek CM, Drumare I, Defoort-Dhellemmes S, Wissinger B, et al. (2009) TRPM1 is mutated in patients with autosomal-recessive complete congenital stationary night blindness. Am J Hum Genet 85:720-729.

Bazhin AV, Schadendorf D, Willner N, De Smet C, Heinzelmann A, Tikhomirova NK, Umansky V, Philippov PP, Eichmüller SB (2007) Photoreceptor proteins as cancer-retina antigens. Int J Cancer 120:1268-1276.

Bellone RR, Brooks SA, Sandmeyer L, Murphy BA, Forsyth G, Archer S, Bailey E, Grahn B (2008) Differential gene expression of TRPM1, the potential cause of congenital stationary night blindness and coat spotting patterns (LP) in the Appaloosa horse (Equus caballus). Genetics 179:1861-1870.

Bellone RR, Forsyth G, Leeb T, Archer S, Sigurdsson S, Imsland F, Mauceli E, Engensteiner M, Bailey E, Sandmeyer L, Grahn B, Lindblad-Toh K, Wade CM (2010) Fine-mapping and mutation analysis of TRPM1: a candidate gene for leopard complex (LP) spotting and congenital stationary night blindness in horses. Brief Funct Genomics 9:193-207.

Berson EL, Lessell S (1988) Paraneoplastic night blindness with malignant melanoma. Am J Ophthalmol 106:307-311.

Dhingra A, Jiang M, Wang TL, Lyubarsky A, Savchenko A, Bar-Yehuda T, Sterling P, Birnbaumer L, Vardi N (2002) Light response of retinal ON bipolar cells requires a specific splice variant of $G \alpha_{0}$. J Neurosci 22: $4878-4884$.

Dhingra A, Sulaiman P, Xu Y, Fina ME, Veh RW, Vardi N (2008) Probing neurochemical structure and function of retinal ON bipolar cells with a transgenic mouse. J Comp Neurol 510:484-496.

Duncan LM, Deeds J, Cronin FE, Donovan M, Sober AJ, Kauffman M, McCarthy JJ (2001) Melastatin expression and prognosis in cutaneous malignant melanoma. J Clin Oncol 19:568-576.

Hammock L, Cohen C, Carlson G, Murray D, Ross JS, Sheehan C, Nazir TM, Carlson JA (2006) Chromogenic in situ hybridization analysis of melastatin mRNA expression in melanomas from American Joint Committee on Cancer stage I and II patients with recurrent melanoma. J Cutan Pathol 33:599-607.

Hartmann TB, Bazhin AV, Schadendorf D, Eichmüller SB (2005) SEREX identification of new tumor antigens linked to melanoma-associated retinopathy. Int J Cancer 114:88-93.

Heckenlively JR, Ferreyra HA (2008) Autoimmune retinopathy: a review and summary. Semin Immunopathol 30:127-134.

Kellner U, Bornfeld N, Foerster MH (1995) Severe course of cutaneous melanoma associated paraneoplastic retinopathy. Br J Ophthalmol 79:746752.

Keltner JL, Thirkill CE (1998) Cancer-associated retinopathy vs recoverinassociated retinopathy. Am J Ophthalmol 126:296-302.

Keltner JL, Thirkill CE, Yip PT (2001) Clinical and immunologic characteristics of melanoma-associated retinopathy syndrome: eleven new cases and a review of 51 previously published cases. J Neuroophthalmol 21:173-187.

Koike C, Obara T, Uriu Y, Numata T, Sanuki R, Miyata K, Koyasu T, Ueno S, Funabiki K, Tani A, Ueda H, Kondo M, Mori Y, Tachibana M, Furukawa $\mathrm{T}$ (2010) TRPM1 is a component of the retinal ON bipolar cell transduction channel in the mGluR6 cascade. Proc Natl Acad Sci U S A 107:332-337.

Lei B, Bush RA, Milam AH, Sieving PA (2000) Human melanomaassociated retinopathy (MAR) antibodies alter the retinal ON-response of the monkey ERG in vivo. Invest Ophthalmol Vis Sci 41:262-266.

Li Z, Sergouniotis PI, Michaelides M, Mackay DS, Wright GA, Devery S, Moore AT, Holder GE, Robson AG, Webster AR (2009) Recessive mutations of the gene TRPM1 abrogate ON bipolar cell function and cause complete congenital stationary night blindness in humans. Am J Hum Genet 85:711-719.

Lu Y, Jia L, He S, Hurley MC, Leys MJ, Jayasundera T, Heckenlively JR (2009) Melanoma-associated retinopathy: a paraneoplastic autoimmune complication. Arch Ophthalmol 127:1572-1580.

McCall MA, Gregg RG (2008) Comparisons of structural and functional abnormalities in mouse b-wave mutants. J Physiol 586:4385-4392.

Milam AH, Saari JC, Jacobson SG, Lubinski WP, Feun LG, Alexander KR (1993) Autoantibodies against retinal bipolar cells in cutaneous melanoma-associated retinopathy. Invest Ophthalmol Vis Sci 34:91-100.

Morgans CW, Zhang J, Jeffrey BG, Nelson SM, Burke NS, Duvoisin RM, Brown RL (2009) TRPM1 is required for the depolarizing light response in retinal ON-bipolar cells. Proc Natl Acad Sci U S A 106:19174-19178.

Morgans CW, Brown RL, Duvoisin RM (2010) TRPM1: the endpoint of the mGluR6 signal transduction cascade in retinal ON-bipolar cells. Bioessays 32:609-614.

Potter MJ, Adamus G, Szabo SM, Lee R, Mohaseb K, Behn D (2002) Autoantibodies to transducin in a patient with melanoma-associated retinopathy. Am J Ophthalmol 134:128-130.

Shen Y, Heimel JA, Kamermans M, Peachey NS, Gregg RG, Nawy S (2009) A transient receptor potential-like channel mediates synaptic transmission in rod bipolar cells. J Neurosci 29:6088-6093.

Shiraga S, Adamus G (2002) Mechanism of CAR syndrome: anti-recoverin antibodies are the inducers of retinal cell apoptotic death via the caspase 9- and caspase 3-dependent pathway. J Neuroimmunol 132:72-82.

van Genderen MM, Bijveld MM, Claassen YB, Florijn RJ, Pearring JN, Meire FM, McCall MA, Riemslag FC, Gregg RG, Bergen AA, Kamermans M (2009) Mutations in TRPM1 are a common cause of complete congenital stationary night blindness. Am J Hum Genet 85:730-736.

Vardi N (1998) Alpha subunit of Go localizes in the dendritic tips of ON bipolar cells. J Comp Neurol 395:43-52.

Vardi N, Sterling P (1994) Subcellular localization of GABA A receptor on bipolar cells in macaque and human retina. Vision Research 34:1235-1246.

Weinstein JM, Kelman SE, Bresnick GH, Kornguth SE (1994) Paraneoplastic retinopathy associated with antiretinal bipolar cell antibodies in cutaneous malignant melanoma. Ophthalmology 101:1236-1243.

Xu XZ, Moebius F, Gill DL, Montell C (2001) Regulation of melastatin, a TRP-related protein, through interaction with a cytoplasmic isoform. Proc Natl Acad Sci U S A 98:10692-10697. 